\title{
Index decomposition analysis of urban crop water footprint
}

X. Zhao ${ }^{1 *}$, M. R. Tillotson ${ }^{2}$, Y.W. Liu ${ }^{3}$, W. Guo ${ }^{4}$, A.H. Yang ${ }^{5}$, Y.F. Li $^{1}$

$3 \quad{ }^{1}$ Key Laboratory of Integrated Regulation and Resource Development on Shallow Lak

4 es, Ministry of Education, College of Environment, Hohai University, Nanjing

5 210098, China

6 2water@leeds, School of Civil Engineering, University of Leeds, Leeds LS2 9JT,

7 United Kingdom;

$8 \quad{ }^{3}$ School of Nature Conservation, Beijing Forestry University, Beijing 100083, China

$9{ }^{4}$ School of Environmental and Chemical Engineering, North China Electric Power

10 University, Beijing 102206, China

$11{ }^{5}$ Water Stewardship of Living Yangtze ProgrammeBeijing Office, World Wide Fund 12 for Nature, Beijing 100037 P.R. China

\section{Abstract}

Rapid urbanization has resulted in often unplannedincreasesinpopulation, and food demand in cities.Historically, hinterlands to thesecitieshave acted as breadbaskets producingfood to theurban residents. Accordingly, a large amount of available freshwater has been needed to support these croplands. However, the rapid expansion of cities in developing countries has significantly changed both the croplands around cities and the water demand. It is thus important to quantitatively investigate the water-food nexus of cities related to the changing hinterland

21 agriculture. Water footprint is an indicator reflecting the human impact on water. In this study, we quantified both the blue and green water footprint of major crop

23 products in Suzhou city, China usinga bottom-up accounting method. A novel decomposition analysis wascarried out with a Logarithmic Mean Divisia Index(LMDI) method to study the driving forces that changed the water footprint during the period

\footnotetext{
* Corresponding author. Tel.: +86 10 13621310973. E-mail address: xuzhao@hhu.edu.cn; xu.zhao.water@hotmail.com (X. Zhao).
} 
26 2001-2010. The drivers weredesigned to reflect the factors related to farmland, such 27 as yield and crop area. This is different from previous decomposition analyses, which 28 focused on economic factors such asGDP. The results show that the crop water 29 footprint of Suzhou city has seen a general decreasing trend between2001 and2010. 30 The decomposition analysis showed that the declineof crop areawas the main driver 31 that decreased the crop water footprint, followed bythe virtual water content (water 32 consumption per unit of production). In contrastthe changes of crop combination and 33 yield contributed to an increase in the crop water footprint. Although the shrink of 34 urban croplands decreased the water footprint of crop products. Cities' increasing 35 demand for food will increase the crop water footprint of consumption. This will 36 increase the dependence of cities on external water footprint of crop products (water 37 embodied in imported crops), whichmay impact upon food security in cities in the 38 long term.

39 Keywords:hinterland agriculture, crop water footprint, decomposition analysis, 40 LMDI 


\section{Introduction}

Cities constitute primary agglomerations of people.In 2014 54\% of the world's population lived in cities, and this is forecast to rise to $66 \%$ by 2050 (United Nations, 2014). One of the key challenges faced by cities around the world is to meet food demand for residents (Barthel and Isendahl, 2013; Lynch et al., 2013). Traditionally, farmlands around cities, also known as hinterlands,have supportedthis food demand (Zezza and Tasciotti, 2010). Such urban agriculture has historicallybeen critical to achieving food security in cities (Lynch et al., 2013).However, the huge water demandassociated with agricultural productionconflicts with the increasing water demand due to urban population growth. Current trends of rapid expansion of cities, especially in developing countries, has significantly changed both the croplands around cities and the associated water demand.To the best of our knowledge, few studies have focused onthe interactions between hinterland agriculture and the water demandassociated with urbanization.

The water-food nexus of cities related to changing hinterland agriculture can be evaluated using the water footprint (WF)concept.The WF is defined as the volume of freshwater used during the production process (Hoekstra et al., 2011). Ithas been widely used in quantifying and assessing freshwater consumption in crop production (e.g. Chapagain and Hoekstra, 2011; Mekonnen and Hoekstra, 2011; Vanham et al., 2013). Freshwater refers to both green water and blue water. Green water is the precipitation on land which does not run-off or recharge groundwater but is stored in the soil or remains on the surfaceof the soil or vegetation. The accounting of green water footprint is closely related to crop growth. The blue water for crop growth can be substituted by green water, so a complete picture can be obtained only by accountingfor both(Hoekstra et al., 2011).A bottom-up methodis widely applied to accounting for the crop WF, whichstarts from the smallest unit feasible in assessing the WF and aggregates each unit to the desired scale and period(Yang et al., 2013). 
69 hinterland usage, with drivers such as water productivity, yield, agricultural area etc., 70 to understand the interactions between hinterland agriculture changes and freshwater 71 consumption. In recent years, decomposition analyses has been applied to study the 72 driving forces or determinants thatunderlie changes to the $\mathrm{WF}$ (Feng et al., 2015).For 73 example, Zhang (2012)decomposed the effects of contributing factors to Beijing's 74 WFchanges during 1997-2007. The contributing factors were technological, economic 75 system efficiency, scale, and structural effects. Zhao et al. (2014) investigated the 76 impact of population, affluence, urbanization level, and diet factors on the WF of 77 agricultural products in China based on an extended STIRPAT model. Theabove 78 decomposition analyses, however, werenot designed to reflect the factors related to 79 changing farmland, such as crop yield or area, and thus were unable to identify the 80 interrelationships between hinterland agricultural changes and associated water 81 consumption. In addtion, green water was excluded from most decomposition analyses of WF changes.

83 In the context of increasing urbanization in developing countries, this study has 84 quantitatively investigated the water-food nexus in Suzhou city, China by performing 85 a novel decomposition analysis with a Logarithmic Mean Divisia Index (LMDI) 86 model. The aim was to study the contributing factors to urban crop WF changes, 87 including virtual water content (reciprocal of water productivity), yield, crop structure, 88 and crop area. To best of our knowledgethe driving forces related to crop production 89 that changes both green and blue WF has beenrarely reported. The driving forces and 90 the implications to water-food security at urban scale are also discussed. 


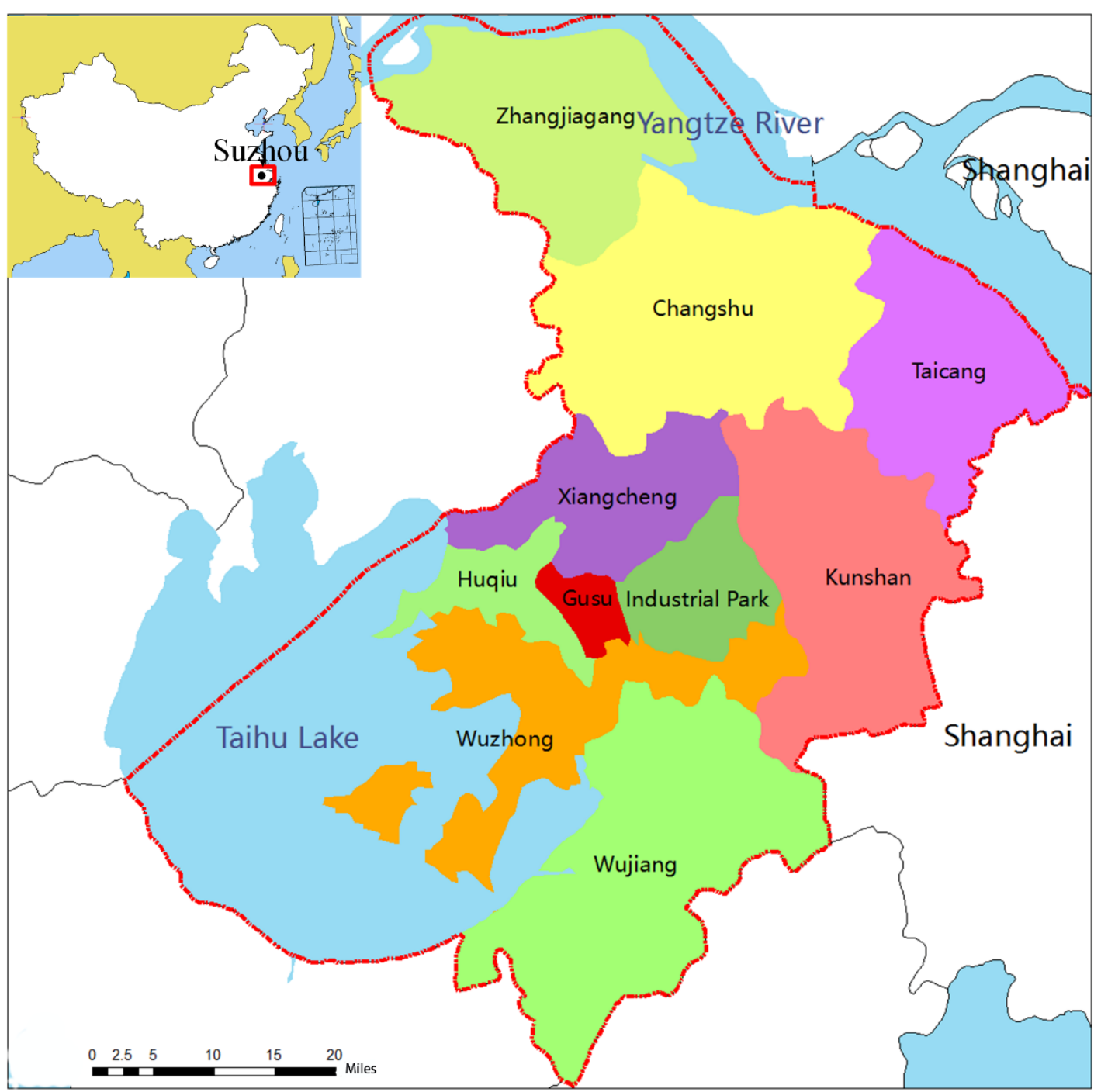

Fig. 1. Location of Suzhou city, China

Suzhou city is located in the Taihu Lake Basin,whichis a subtropical humid area of plentiful rainfall. The annual available water resource in Suzhou is 2.98 billion $\mathrm{m}^{3}$ (in 2010).The total administrative area of Suzhou is $8,488 \mathrm{~km}^{2}$, with $3,609 \mathrm{~km}^{2}$ covered by water (Suzhou Water Resources Bureau, 2010). Lake Taihu, a large shallow freshwaterlake in the lower Yangtze Delta, is close to Suzhou (Fig. 1), and is the main water resource for Suzhou. Significant nutrient pollution from wastewater discharges, along with agricultural run-off from the northwestern shores flows into Lake Taihu. Nutrient concentrations decrease with the current towards the eastern and 
southern reaches of the lake which,as a result, have better water quality i.e. the reaches close to Suzhou city, despite extensive blue-green algae problems in the northwestern part of the lake (Hu et al., 2010).

Suzhou is an ideal case for illustrating how hinterland agriculture can be changed through urbanization and industrialization. Although in contemporary China, Suzhou is known as an industrialized city withmany high-tech industries, it was until the 1980's on ofChina's grain production center. The Taihu Lake Basinhas long been known as "the land of rice and fish" in China.Agriculture in the Taihu Lake Basin sustained high productivity for more than nine centuries (Ellis and Wang, 1997). As such, Suzhou has historically had a large amount of hinterland agriculture dedicated to producing rice and other grain products for both local consumption and export to other regions in China. After the foundation of the People’s Republic of China in 1949, Suzhou was established as a grain production base(Wang et al., 2015). In 1984, the sown area was about $5000 \mathrm{~km}^{2}$ withgrain production peaking at 3.1 million tons(Suzhou Statistics Bureau, 2011). Since then Suzhou has accelerated its industrialization transformation process bycreating a series of industrial park and development zones to stimulate industrial development and attract Foreign Direct Investment (Wang et al., 2015). Today, Suzhou has become one of the wealthiest industrial cities in China. In 2010, GDP in Suzhou ranked $5^{\text {th }}$ among China's 337 cities, following the mega-cities of Beijing, Shanghai, Guangzhou, and Shenzhen. Per capita GDP was about 87,607 CNY (about 12,800 US dollars)(Suzhou Statistics Bureau, 2011).Urbanization in Suzhou, as withother Chinese cities,has experienced land grab and population growth, which have substantial impacts on hinterland agriculture.

Despite its location in a subtropical and humid area, Suzhou as a developed city in China faces water stress. We evaluated water stress in Suzhou during 2007-2010 with two well-known water scarcity indices. The Falkenmark Indexevaluates water stress through the total annual renewable water resource per capita(Falkenmark et al., 
130 1989), and the "Criticalityratio" evaluates water stress using the ratio of total annual 131 withdrawals to renewable water resources(Alcamo et al., 2000). The classification of 132 both indices was adjusted according to Zeng (2013) and Zhao (2016) following 133 China's water endowment. As a result, four classifications weregenerated with $\mathrm{C}$ as 134 the"Criticalityratio" and F as the Falkenmark Index: Absolute Scarcity ( $\mathrm{C}>1$ or $\mathrm{F}<$ $135500 \mathrm{~m}^{3}$ /capita); Scarcity (1>C > 0.4 or $1000 \mathrm{~m}^{3} /$ capita $>$ F $>500 \mathrm{~m}^{3} /$ capita); Stress $136\left(0.4>\right.$ C $>0.2$ or1700 m³/capita $>$ F $>1000 \mathrm{~m}^{3} /$ capita $)$; and No Stress ( $<0.2$ orF $>$ $1371700 \mathrm{~m}^{3}$ /capita). The results for theCriticality ratio show the highest level of water 138 stress in Suzhou (Table 1), while the results for the Falkenmark Index show the 139 second highest level of water stress during 2007-2009, and the highest level in 2010.

140 These results suggest that intensive water use and high population density are the 141 main causes of Suzhou's water stress.

Table 1 Results of water scarcity indices in Suzhou city

\begin{tabular}{cccccc}
\hline Year & $\begin{array}{c}\text { Annual renewable water resources(billion } \\
\mathbf{m}^{\mathbf{3}} \text { ) }\end{array}$ & Population & $\begin{array}{c}\text { Water withdrawal } \\
\text { (billion } \mathbf{~ m}^{\mathbf{3}}\end{array}$ & $\begin{array}{c}\text { Falkenmark Index } \\
\text { (F) }\end{array}$ & $\begin{array}{c}\text { Criticality Ratio } \\
\text { (C) }\end{array}$ \\
\hline 2007 & 3.2 & 6244311 & 7.7 & 515 & 2.3 \\
2008 & 3.3 & 6297530 & 7.5 & 522 & 2.3 \\
2009 & 4.4 & 6332903 & 7.7 & 702 & 1.7 \\
2010 & 3.0 & 6376558 & 7.8 & 468 & 2.6 \\
\hline
\end{tabular}

\section{3. Method and data} indirect water requirement for crop production, i.e. the water required in production of upstream products only takes a small share of the total crop WF(Zhao et al., 2009),

148 thus is ignored in this study. A bottom-up method to quantify the WF of crop products 149 can be expressed as follows:

$$
W F_{\text {tot }}=W F_{g}+W F_{b}=\sum_{i}\left[C W R_{g . i} \cdot A_{i}\right]+\sum_{i}\left[C W R_{b . i} \cdot A_{i}\right](1)
$$

151 Where $W F_{\text {tot }}, W F_{\mathrm{g}}$ and $W F_{b}$ refer to the total, green and blue water footprint of 
crops, $i$ is the type of crops planted, $A_{i}$ is the plant area of crop $i, C W R_{g . i}$ and $C W R_{\mathrm{b} . i}$ are annual green and blue crop water requirements per hectare of crop $i$. Crop water requirement can be calculated using the CROPWAT modeldeveloped by the Food and Agriculture Organization(FAO) (available at http://www.fao.org/nr/water/infores databases cropwat.html). The CROPWAT model takes into account both rainfed and irrigated conditions. So in the CROPWAT model, the green crop water requirement is obtained through quantifying effective rainfall, while the blue crop water requirement is obtained through quantifying irrigation.

\subsection{LMDI model}

We used the LMDImodel to decompose the WF of crops in Suzhou city. The LMDI method was initially developed by Ang and Liu (2001), and has been widely used in analyzing the driving forces of carbon dioxide $\left(\mathrm{CO}_{2}\right)$ emissions or energy efficiency (e.g. Ang, 2004; Dai and Gao, 2016; Fernández González et al., 2014; Liu et al., 2012), and a small number of applications in analyzing WF changes (Xu et al., 2015; Zhao and Chen, 2014). The method has the advantages of expressing in a simple form with no residual errors, so has been recommended for general use (Ang, 2004).

In this study, we redesigned the driving forces of the crop WF to reflect the interrelationships between urban agriculture and associated freshwater consumption. The total WF of crops in Suzhou was decomposed into four driving forces: virtual water content, yield, crop structure, and crop area. Virtual water content (VWC) is the amount of water consumed to produce a unit ofeach crop, which is also the reciprocal of water productivity. Yield is production volume per unit area. Crop structure is the proportion of specific crop area to total area of all crops, and crop area is the total planting area for all crops. The total WF of crops can be expressed with the above four driving forces as follows: 


$$
W F(\mathrm{t})=\sum_{i}\left[V_{i}(\mathrm{t}) \cdot Y_{i}(\mathrm{t}) \cdot S_{i}(\mathrm{t}) \cdot A(\mathrm{t})\right]=\sum_{i}\left[\frac{W F_{i}(\mathrm{t})}{P_{i}(\mathrm{t})} \frac{P_{i}(\mathrm{t})}{A_{i}(\mathrm{t})} \frac{A_{i}(\mathrm{t})}{A(\mathrm{t})} A(\mathrm{t})\right]
$$

179 Where $W F(\mathrm{t})$ is the water footprint of all crops, $V_{i}(\mathrm{t}), Y_{i}(\mathrm{t})$, and $S_{i}(\mathrm{t})$ represent 180 VWC, yield, and crop structure for crop $i$ in year trespectively. $A(\mathrm{t})$ is the total crop 181 area in year t. $P_{i}(\mathrm{t})$ is the production volume of crop $i$ in year $\mathrm{t}$, and $A_{i}(\mathrm{t})$ is the crop 182 area of crop iin year t. According to LMDI, the variation of WF ( $\triangle W F$ ) from year 0 to year $t$ can be decomposed into four parts: the variation of WF caused by change in VWC $\left(\Delta W F_{v}\right)$, 185 the variation of WF related to change in yield $\left(\Delta W F_{y}\right)$, the variation of WF which is 186 due to change in the proportion of a crop area in the total area $\left(\Delta W F_{s}\right)$, and the 187 variation of WF caused by changes to the total area $\left(\Delta W F_{a}\right)$. The decomposition form 188 is shown in Eq. (3):

$$
\Delta W F=W F(t)-W F(0)=\Delta W F_{v}+\Delta W F_{s}+\Delta W F_{y}+\Delta W F_{a}
$$

The four driving forces in Eq. (3) can be quantified as:

$$
\begin{aligned}
& \Delta W F_{\mathrm{v}}=\sum_{i}\left[\varphi\left[W F_{i}(\mathrm{t}), W F_{i}(0)\right] \ln \frac{V_{i}(\mathrm{t})}{V_{i}(0)}\right] \\
& \Delta W F_{s}=\sum_{i}\left[\varphi\left[W F_{i}(\mathrm{t}), W F_{i}(0)\right] \ln \frac{S_{i}(\mathrm{t})}{S_{i}(0)}\right]
\end{aligned}
$$

194

$$
\Delta W F_{y}=\sum_{i}\left[\varphi\left[W F_{i}(\mathrm{t}), W F_{i}(0)\right] \ln \frac{Y_{i}(\mathrm{t})}{Y_{i}(0)}\right] \quad(6)
$$

$$
\Delta W F_{a}=\sum_{i}\left[\varphi\left[W F_{i}(\mathrm{t}), W F_{i}(0)\right] \ln \frac{A(\mathrm{t})}{A(0)}\right]
$$

195 where function $\varphi\left[W F_{i}(\mathrm{t}), W F_{i}(0)\right]$ is the logarithmic average of two positivenumbers 196 $W F_{i}(\mathrm{t})$ and $W F_{i}(0)$ which are given by: 


$$
\varphi\left[W F_{i}(\mathrm{t}), W F_{i}(0)\right]=\left\{\begin{array}{l}
\frac{W F_{i}(\mathrm{t})-W F_{i}(0)}{\ln W F_{i}(\mathrm{t})-\ln W F_{i}(0)}, W F_{i}(\mathrm{t}) \neq W F_{i}(0) \\
W F_{i}(0), W F_{i}(\mathrm{t})=W F_{i}(0)
\end{array}\right.
$$

\subsection{Data source}

In this study, the four main crops in Suzhou wereconsidered: wheat, rice, cotton, 200 and rapeseed. The total cultivated area of the four crops accounted forabout $70 \%$ of 201 the total cultivated area in Suzhou (Suzhou Statistics Bureau, 2011). The input data of 202 the CROPWAT model included climatic, crop and soil parameters. 203 Climaticinputsincluded average maximum and minimum air temperature, 204 precipitation, relative humidity, sunlight duration, radiation and wind speed, which 205 were obtained from the China Meteorological Data Sharing Service System 206 (http://data.cma.cn/).Crop and soil parameters were taken from the default values in 207 the CROPWAT software provided byFAO.The data forcrop production and crop areas 208 were obtained from the Suzhou Statistical Yearbook(Suzhou Statistics Bureau, 2011). 


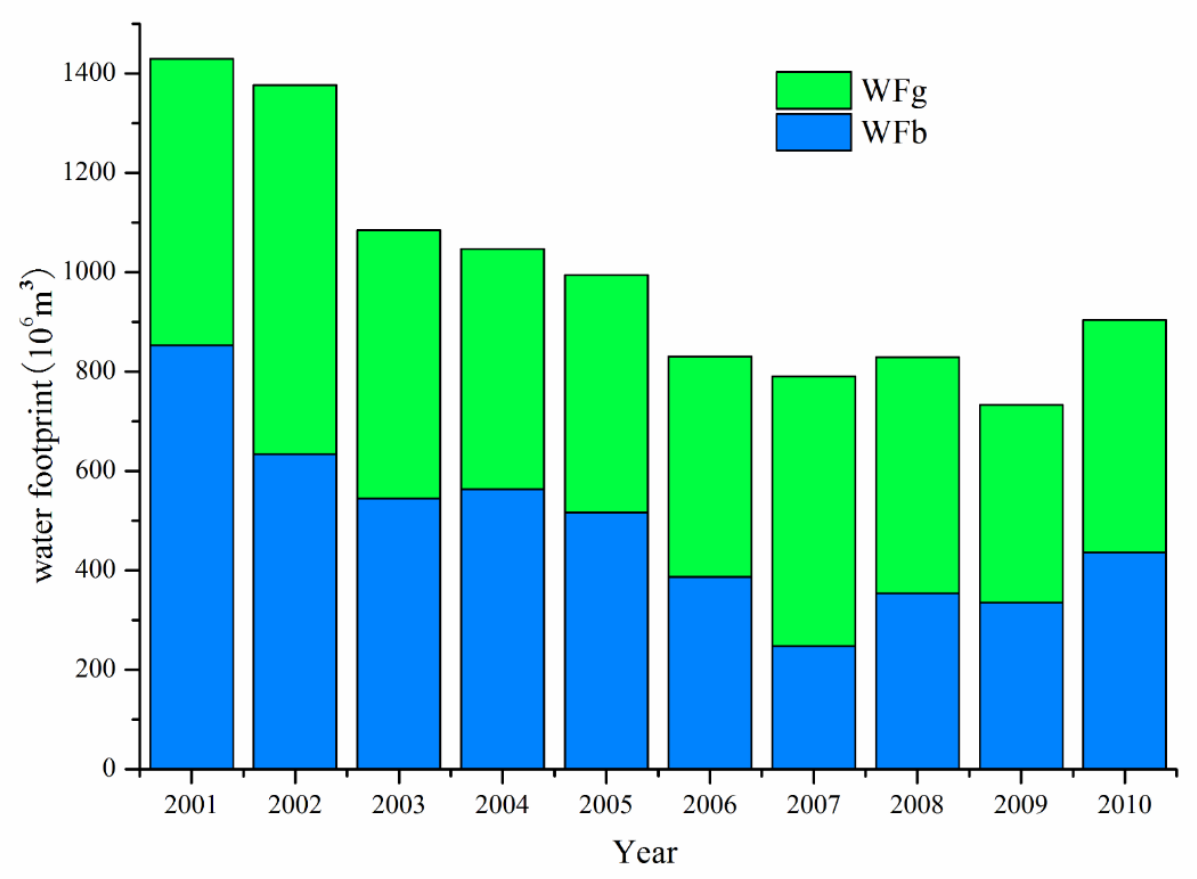

215 incorporating $487.5 \mathrm{~m}^{3}$ of blue WF and $514.4 \mathrm{~m}^{3}$ of green WF. Green WF dominated 216 the WF for wheat, cotton, and rapeseed, accounting for 73\%-79\% of the total WF on 217 average for these three crops. Blue WF dominated the WF of rice, accounting for $62 \%$ 218 of the total WF on average. The average WF forrice took the greatestshare amongst 219 the WF of the four crops studied, accounting for $63 \%$ of the total, followed by the WF 220 of wheat which accounted for $29 \%$ of the total. As shown in Fig.2, the crop WF 221 experienced a general decreasing trend from 2001 to 2010.Specifically, the crop WF 222 experienced continued reduction between2001 and 2007, before fluctuating slightly 223 from 2007 to 2010. Blue WF decreased from 853.04 million $\mathrm{m}^{3}$ in 2001 to 247.53 224 million $\mathrm{m}^{3}$ in 2007, before increasing to 436.38 million $\mathrm{m}^{3}$ in 2010. Green WF 225 fluctuated between 397.41 million $\mathrm{m}^{3}$ to742.75 million $\mathrm{m}^{3}$ duringthe 10 study years. 
226 The biggest share of the blue WF to total WF of crop products was 59.64\% in 2001, 227 and the smallest share was 31.32\% in 2007.

228 4.2. The driving force analysis of crop water footprint changes in Suzhou

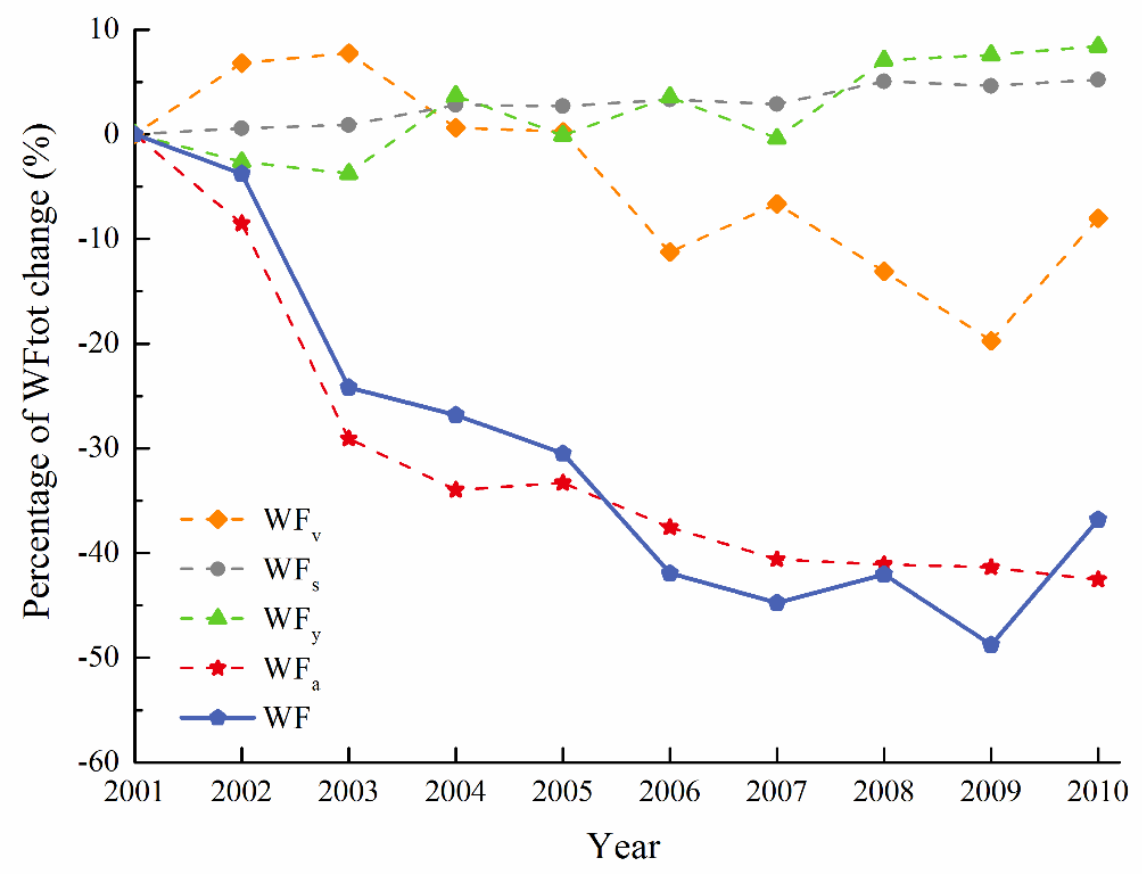

As shown in Fig. 3, the total crop WF decreased by 526 million $\mathrm{m}^{3}$ during 232 2001-2010, withtotal area contributing the most to this reduction. The decrease of 233 total area would have decreased the crop WF by a total of 608 million $\mathrm{m}^{3}$, if other 234 factors (VWC, crop structure, and crop yield) had remained static at 2001 levels. In 235 the study period (2001-2010), area changes were the main driving forces in crop WF 236 reduction. According to Fig. 3, area changes sharplyreduced crop WFfrom 2001 to 237 2004, continued to cause a gentle reduction between 2004 and 2007, finally having 238 less impact between 2007 and 2010. The impact of VWC fluctuated over the study 239 period, but decreased by a total of 115 million $\mathrm{m}^{3}$ of the crop WF during 2001-2010. 240 For example, the VWC decreased the crop WF by 164.52 million $\mathrm{m}^{3}$ during 241 2005-2006, but increased by 167.68 million $\mathrm{m}^{3}$ of the crop WF during 2009-2010.The 
242 change in crop yield and crop structure would have increased the crop WF by 120 and

24375 million $\mathrm{m}^{3}$ respectively. It is obvious that the crop WF growth due to the effects of 244 crop yield and crop structurecould notoffset the crop WF reductionowing to the 245 effects of crop area and VWC.

\subsubsection{Virtual water content effect}

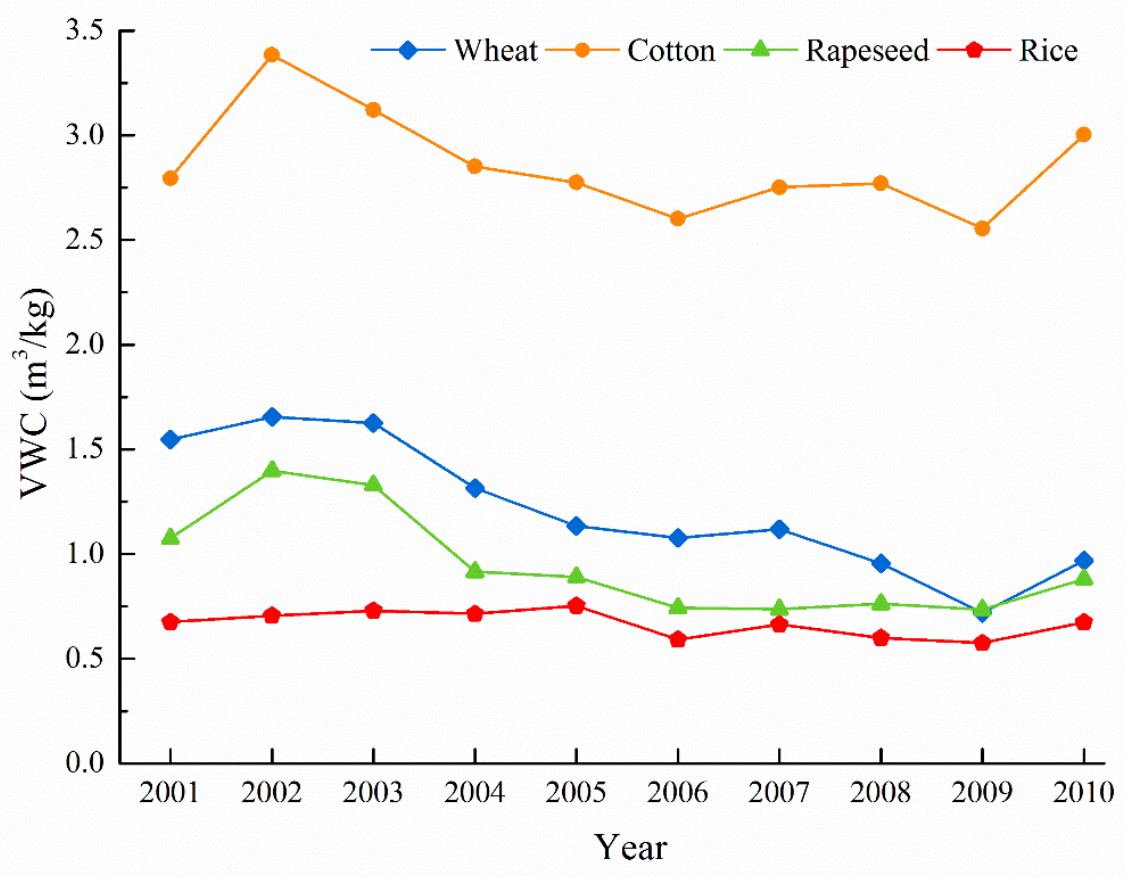

Fig. 4. Virtual water content changes for four majorcrops

Fig. 3 showsthatthe pattern of crop WF change is highly related to the change of 250 the VWC which fluctuated over the study period. Such fluctuation can be linked to 251 changes in climatic factors such as temperature, sunlight, and precipitation 252 etc.Climatic factors can change both crop output and associated water consumption, 253 and as a result, have impact on the VWC. For example, Bocchiolaand Soncini (2013) 254 found that crop yield decreased and the WF increased with increasing temperature and 255 decreasing precipitation. Kang et al. (2009)found that climate change led to changes 256 insoil evaporation and plant transpiration and consequently thecrop growth period 
may be changed having influence on crop water productivity, i.e. the reciprocal of the

258 VWC. Some previous studies assumed the same VWC for different years e.g.(Liu et 259 al., 2007), which ignored the impact of the changing VWC on the crop WF. However, 260 our results show that ignoring the difference of the VWC will lead to noticeable bias 261 for crop WF accounting.

\subsubsection{Crop area effect}

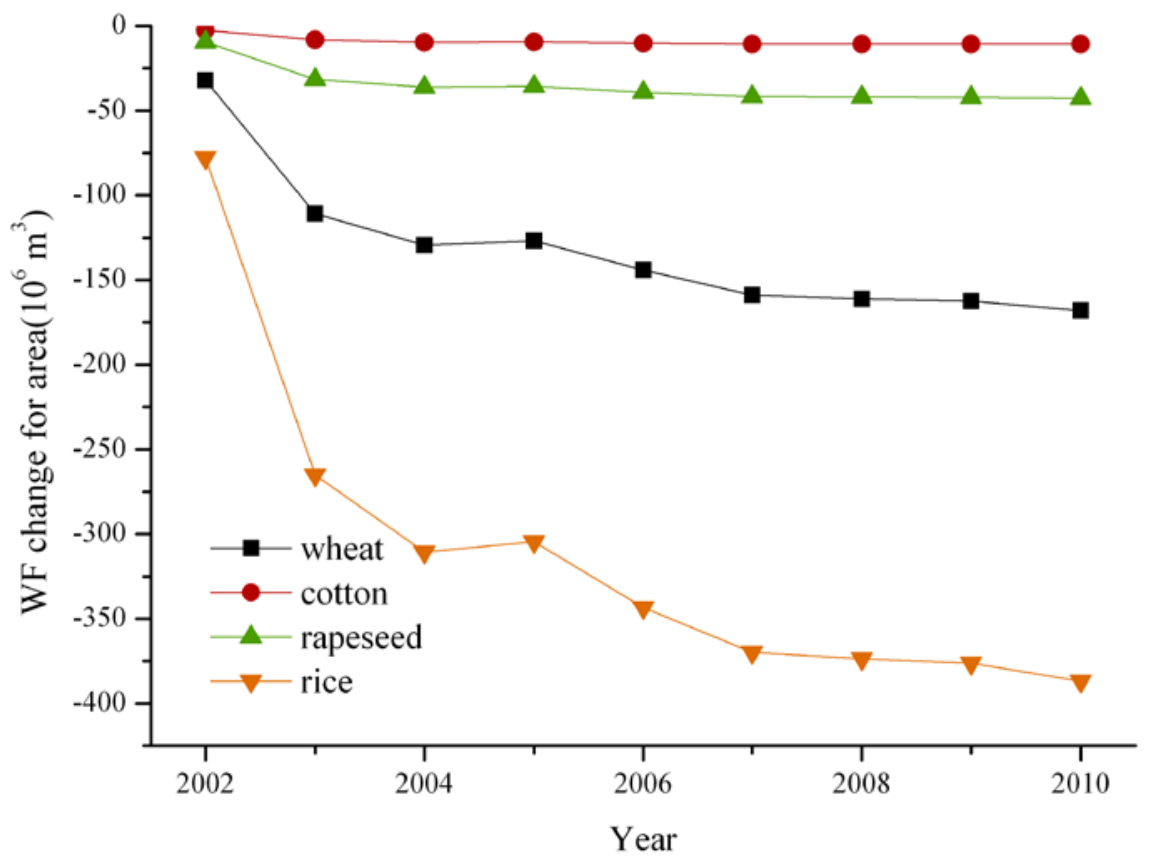

263

During the study period (2001-2010)area changes were the main driving force in crop WF reduction. According to Fig. 3, area changes sharplyreduced crop 267 WFbetween 2001 and 2004, continued to cause a gentle reduction between 2004 and 268 2007, and had less impact from 2007 to 2010. The above changes correlated with crop 269 area changes in Suzhou. The crop area reduction per annum was $136.6 \mathrm{~km}^{2}$ from 2001 270 to 2004, $76 \mathrm{~km}^{2}$ from 2004 to 2007, and $31.6 \mathrm{~km}^{2}$ from 2007 to 2010. The main cause 271 of crop area reduction isattributed to rapid urbanization in China, along with urban 272 land expansion. In urban expansionit is common to see crop land occupied by newly 
273 built urban infrastructure, such as dwellings and factories.Consistent with China's 274 national urbanization trend, the urban land takearound Suzhou in the early 21st 275 century has also undergone rapid expansion(Wang et al., 2015). As a result, 276 agricultural land around Suzhou has shrunk rapidly since 2001. Such reductionshave 277 attracted the attention of government and scientists: a major concern is that rapid 278 urban expansion will threaten food security in China. In 2006,0.12 billion ha of arable 279 land area was set as a cap, i.e. a redline to limit arable land reduction(State Council of 280 the People's Republic of China, 2006). Consequently, the downward trend of crop 281 area has slowed since 2007.

\subsubsection{Crop structure effect}

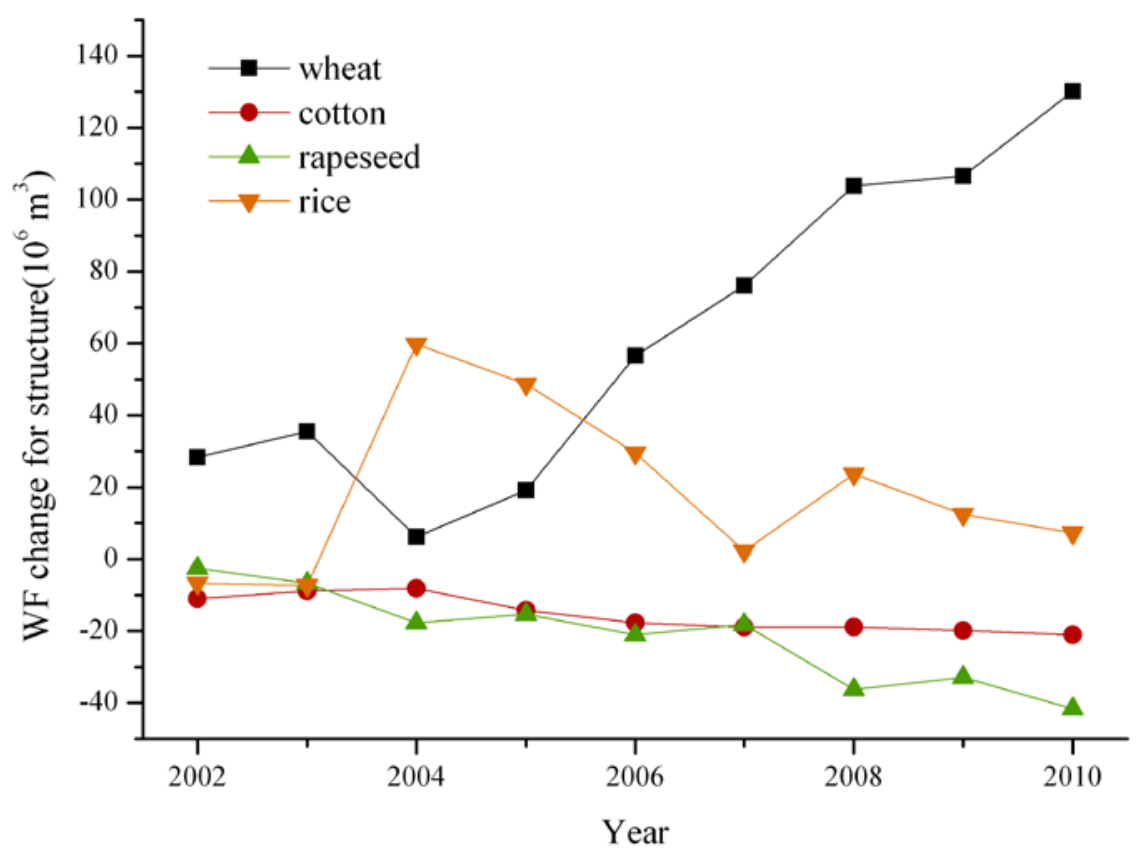

The overall impact of crop structure on crop WF was small but resulted in a steady increase in crop WF during the study period.As shown in Fig. 6, the proportion of wheat area amongstthe major crop areas increased between 2004 and 2010, while the area proportion for the other crops decreased. The increasing crop area proportion 
of wheat possibly reflectsa decreasedlabour force for Suzhou's crop production. In

290 2010, labour costsfor wheat production in Suzhou was the lowest of the four crops at 291 about $1950 \mathrm{CNY} / \mathrm{ha}$ (285 dollars/ha), whilst labour costsfor rapeseed was highest, at 292 about 4440 CNY/ha (650 dollars/ha) (National Development and Reform 293 Commission, 2010). Since the population working on Suzhou's hinterland agriculture 294 decreased by 218 thousand from 2001 to 2010, it is reasonable to infer that more 295 farmers chose to cultivate wheat to overcome labour shortage. Since wheat had the 296 second largest VWC among the four crops studied, and the largest plant area, the 297 increasedproportion of wheat also increased the total WF.

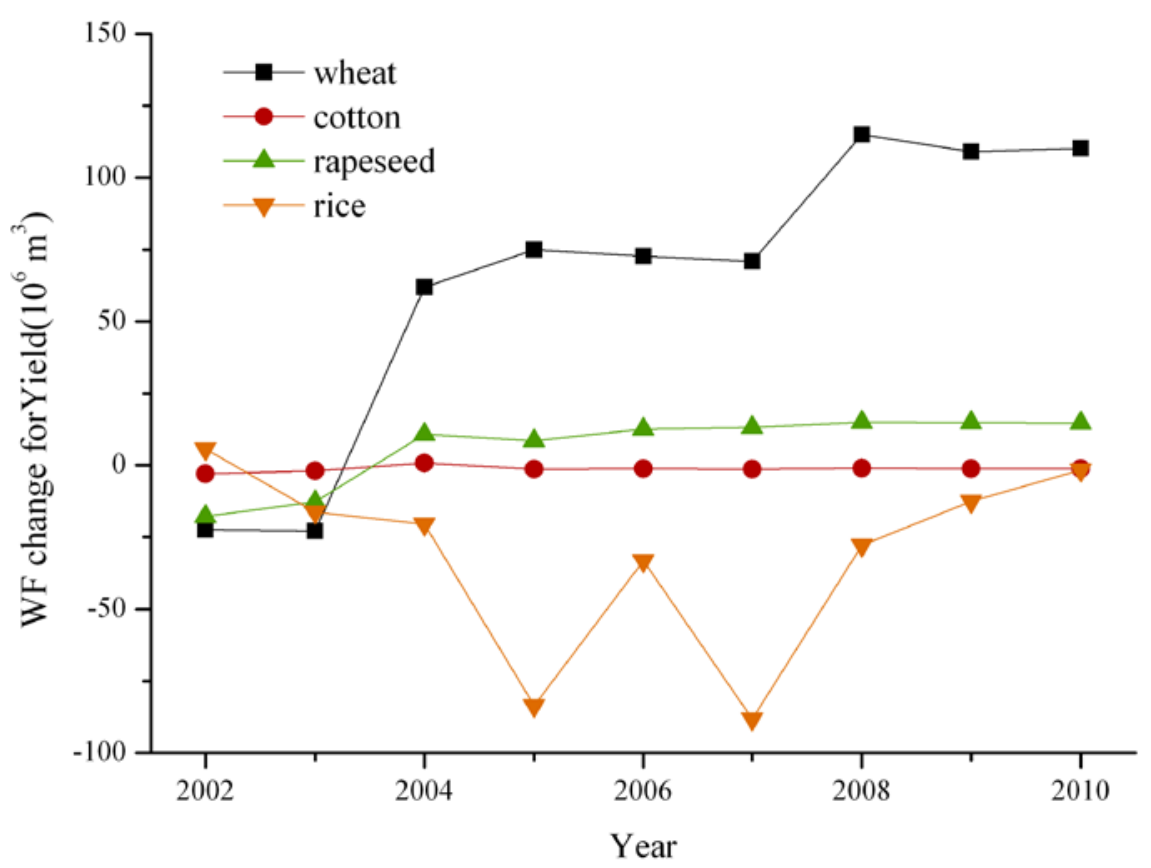
Fig. 7. Contribution of yield to WF changes

From 2001 to 2010yield generally increased crop WF for Suzhou.As shown in Fig. 7the yield of wheat contributed most to crop WF increase, rising from 3,136 ton/thousand ha to 4,727 ton/thousand ha, about a 51\% increase during the study period. It can be inferred that the increase in wheat yield also stimulated the 
305 increased proportion of wheat planting area to the total areas of the four studied 306 crops. The yield for rice decreased in 2005 and 2007, and then increased to reflect 307 the general trend in subsequent years. Crop yield is highly related to climatic 308 factorssuch as radiation, temperature, and precipitation etc. (Liu et al., 309 2016), andwill thus be considered in the decomposition analysis of crop WF in 310 future work.

\section{5. Conclusions}

China has long advocated food self-sufficiency; even developed cities take a significantstakein governing agricultural land use. Such efforts provide an effective

314 way of supporting food security, but also increase the pressure on urban water 315 supplies. This study has proposed a new set of parameters including virtual water 316 content, yield, crop structure, and crop area to reflect the interactions of hinterland agriculture and water demand on a developed Chinese city.Ourattempt highlights the

318 importance of incorporating drivers related to agricultural land changes into urban 319 land and water management, thus cansupport decision making in balancing the 320 trade-offs between local food demand and water resource allocation. Decreased WF 321 of crop products mitigate urban water stress to an extent, but increase the reliance of 322 the city on external water supplies which can be acquired through both physical and 323 virtual forms. Research and modelling on the sustainability and equity for large cities 324 relying on external water supply is an urgent issue.

\section{Acknowledgement}

326 The research was supported by the Fundamental Research Funds for the Central 327 Universities(2016B13814), Chinese National Science Foundation (51579071, 328 51379061, 41323001, 51539003), Jiangsu Province National Science Foundation 329 (BK20131370), and National Science Funds for Creative Research Groups of China 330 (No. 51421006); the program of Dual Innovative Talents Plan and Innovative 

Hydrology-Water Resources and Hydraulic Engineering.

\section{Reference}

334

335

336

337

338

339

340

341

342

343

344

345

346

347

348

349

350

351

352

353

354

355

356

357

358

359

360

361

362

363

364

365

366

367

368

369

Alcamo, J., Henrichs, T., Rösch, T., 2000. World water in 2025: Global modeling and scenario analysis for the world commission on water for the 21st century. Center for Environmental Systems Research, University of Kassel.

Ang, B.W., 2004. Decomposition analysis for policymaking in energy. Energ Policy 32, 1131-1139.

Ang, B.W., Liu, F.L., 2001. A new energy decomposition method: perfect in decomposition and consistent in aggregation. Energy 26, 537-548.

Authro, 2014. World urbanization prospects: The 2014 revision, Highlights (ST/ESA/SER.A/352).

Barthel, S., Isendahl, C., 2013. Urban gardens, agriculture, and water management: Sources of resilience for long-term food security in cities. Ecological Economics 86, 224-234.

Bocchiola, D., Nana, E., Soncini, A., 2013. Impact of climate change scenarios on crop yield and water footprint of maize in the Po valley of Italy. Agricultural Water Management 116, 50-61.

Chapagain, A.K., Hoekstra, A.Y., 2011. The blue, green and grey water footprint of rice from production and consumption perspectives. Ecological Economics 70, 749-758.

Dai, Y., Gao, H.O., 2016. Energy consumption in China's logistics industry: A decomposition analysis using the LMDI approach. Transportation Research Part D: Transport and Environment 46, 69-80.

Ellis, E.C., Wang, S.M., 1997. Sustainable Traditional Agriculture in the Tai Lake Region of China. Agriculture, Ecosystems \& Environment 61, 177-193.

Falkenmark, M., Lundqvist, J., Widstrand, C., 1989. Macro - scale water scarcity requires micro - scale approaches, Natural resources forum. Wiley Online Library, pp. 258-267.

Feng, L., Chen, B., Hayat, T., Alsaedi, A., Ahmad, B., 2015. The driving force of water footprint under the rapid urbanization process: a structural decomposition analysis for Zhangye city in China. Journal of Cleaner Production, In press.

Fernández González, P., Landajo, M., Presno, M.J., 2014. Tracking European Union CO2 emissions through LMDI (logarithmic-mean Divisia index) decomposition. The activity revaluation approach. Energy 73, 741-750.

Hoekstra, A.Y., Chapagain, A.K., Aldaya, M.M., Mekonnen, M.M., 2011. The water footprint assessment manual: Setting the global standard. Earthscan $224 \mathrm{pp}$.

Hu, L., Hu, W., Zhai, S., Wu, H., 2010. Effects on water quality following water transfer in Lake Taihu, China. Ecological Engineering 36, 471-481. 
Kang, Y., Khan, S., Ma, X., 2009. Climate change impacts on crop yield, crop water productivity and food security - A review. Progress in Natural Science 19, 1665-1674. Liu, J., Zehnder, A.J.B., Yang, H., 2007. Historical Trends in China's Virtual Water Trade. Water Int 32, 78-90.

Liu, S.L., Pu, C., Ren, Y.X., Zhao, X.L., Zhao, X., Chen, F., Xiao, X.P., Zhang, H.L., 2016. Yield variation of double-rice in response to climate change in Southern China. European Journal of Agronomy.

Liu, Z., Liang, S., Geng, Y., Xue, B., Xi, F., Pan, Y., Zhang, T., Fujita, T., 2012. Features, trajectories and driving forces for energy-related GHG emissions from Chinese mega cites: The case of Beijing, Tianjin, Shanghai and Chongqing. Energy 37, 245-254.

Lynch, K., Maconachie, R., Binns, T., Tengbe, P., Bangura, K., 2013. Meeting the urban challenge? Urban agriculture and food security in post-conflict Freetown, Sierra Leone. Appl Geogr 36, 31-39.

Mekonnen, M.M., Hoekstra, A.Y., 2011. The green, blue and grey water footprint of crops and derived crop products. Hydrologyand Earth System Sciences 15, 1577-1600.

National Bureau of Statistics of China, 2011. Chinese Statistical Yearbook 2011. China Statistics Press, Beijing, China.

National Development and Reform Commission, 2010. Collection on cost and benefit data of national agricultural products, China Statistics Press.

State Council of the People's Republic of China, 2006. The outline of the 11th Five-year pland of Economy and Social Development. Suzhou Statistics Bureau, 2011. Suzhou Statistical Yearbook. China Statistics Press. Suzhou Water Resources Bureau, 2010. Suzhou Water Resource Bulletin (in Chinese). China Water Power Press, Beijing. Vanham, D., Mekonnen, M.M., Hoekstra, A.Y., 2013. The water footprint of the EU for different diets. Ecological Indicators 32, 1-8.

Wang, L., Shen, J., Chung, C.K.L., 2015. City profile: Suzhou - a Chinese city under transformation. Cities 44, 60-72.

Xu, Y., Huang, K., Yu, Y., Wang, X., 2015. Changes in water footprint of crop production in Beijing from 1978 to 2012: a logarithmic mean Divisia index decomposition analysis. Journal of Cleaner Production 87, 180-187.

Yang, H., Pfister, S., Bhaduri, A., 2013. Accounting for a scarce resource: virtual water and water footprint in the global water system. Current Opinion in Environmental Sustainability 5, 599-606.

Zeng, Z., Liu, J., Savenije, H.H.G., 2013. A simple approach to assess water scarcity integrating water quantity and quality. Ecological Indicators 34, 441-449.

Zezza, A., Tasciotti, L., 2010. Urban agriculture, poverty, and food security: Empirical evidence from a sample of developing countries. Food Policy 35, 265-273.

Zhang, Z., Shi, M., Yang, H., 2012. Understanding Beijing's water challenge: A decomposition analysis of changes in Beijing's water footprint between 1997 and 
412 2007. Environmental Science \&Technology 46, 12373-12380.

413 Zhao, C., Chen, B., 2014. Driving force analysis of the agricultural water footprint in 414 China based on the LMDI method. Environmental Science \& Technology 48, 415 12723-12731.

416 Zhao, C., Chen, B., Hayat, T., Alsaedi, A., Ahmad, B., 2014. Driving force analysis of 417 water footprint change based on extended STIRPAT model: Evidence from the 418 Chinese agricultural sector. Ecological Indicators 47, 43-49.

419 Zhao, X., Chen, B., Yang, Z.F., 2009. National water footprint in an input-output 420 framework- a case study of China 2002. Ecological Modelling 220, 245-253.

421 Zhao, X., Liu, J., Yang, H., Duarte, R., Tillotson, M.R., Hubacek, K., 2016. Burden 422 shifting of water quantity and quality stress from megacity Shanghai. Water Resoures 423 Research, 10.1002/2016WR018595. 